\title{
Experiences of Finnish SMEs Sourcing From China*
}

\author{
Matti Muhos, Lingyun Wang, Pekka Kess \\ University of Oulu, Oulu, Finland \\ Maaria Pennanen \\ Vacon Plc., Vaasa, Finland \\ Tommi Karjalainen \\ Akkuser Ltd., Nivala, Finland
}

\begin{abstract}
The aim of this study is to describe the experiences of Finnish SMEs (small and medium-sized enterprises) sourcing from China. The study was conducted as part of a project funded by the European Regional Development Fund (ERDF). SMEs are expected to face challenges in international sourcing due to their limited resources and experience in international business. Moreover, Finnish SMEs are expected to face context-specific challenges due to their geographical and cultural distance to the market. This case study seeks to find answers to the following research questions: What are the drivers for Finnish SMEs to start sourcing from China? What kinds of challenges were faced in sourcing from China? These research questions are answered through eight-case studies of Finnish SMEs in which sourcing from China plays a significant role. As a result of this study, the main drivers and challenges related to the process were analyzed and evaluated. The SMEs analyzed here faced special drivers and challenges related to sourcing from China-more drivers than challenges were pointed out. SMEs could strongly benefit from external support tailored to their context-specific needs. The results of this analysis are mainly applicable to SMEs in the Finnish context.
\end{abstract}

Keywords: international sourcing, internationalization, small and medium-sized enterprises (SMEs), China

\section{Introduction}

This study is part of a project funded by the European Regional Development Fund (ERDF). Economic growth has increased rapidly for many decades, and China offers many possibilities for large and small companies. China is the world's fastest-growing economy, and its economy has grown more or less steadily over the last 30 years (Kettunen, Lintunen, Lu, \& Kosonen, 2008). China is the second largest economy in the world after the United States, and accounts for $7.5 \%$ of the world's total economic activity. This study focuses on sourcing from China. The intention is to support small and medium-sized enterprises (SMEs) planning to

\footnotetext{
* The study was conducted as part of an EU-funded project. The authors are grateful for the project funding support provided by the Finnish Centres for Economic Development, Transport and the Environment (ELY-Keskus) and the European Regional Development Fund. We highly appreciate the companies involved in the study for sharing their experiences.

Matti Muhos, Dr. Eng., Research Director, Oulu Southern Institute, University of Oulu.

Lingyun Wang, Ph.D., Department of Industrial Engineering and Management, University of Oulu.

Pekka Kess, Dr. Sc., Dr. Eng., Department of Industrial Engineering and Management, University of Oulu.

Maaria Pennanen, M.Sc. Eng., M.Sc. Econ., Research and Development, Vacon Plc..

Tommi Karjalainen, M.Sc., Operative Management, Akkuser Ltd..

Correspondence concerning this article should be addressed to Matti Muhos, University of Oulu, Oulu Southern Institute, Pajatie 5, FI-85500 Nivala, Finland. E-mail: matti.muhos@oulu.fi.
} 
start collaborating with Chinese suppliers. The focus is on Finnish SMEs.

Multinational corporations have become increasingly interested in the Chinese market for goods and services. In China, Western firms face a business environment that differs from their home market. However, these firms can learn about this market and improve sourcing accordingly. International sourcing refers to purchasing materials, components, and finished products from foreign suppliers. It thrives on globalization, communication technology, and transport system development, as well as the reduction of international trade boundaries (Carlsson, Nordegren, \& Sjöholm, 2005). These issues have developed rapidly in Chinese market recently, making it one of the most attractive sourcing markets. Since most big retailers are now sourcing from China, smaller ones typically wonder whether they should do the same, but are often put off by the complexities of getting started. China is the third largest exporter in the world, so there are plenty of serious and high-quality suppliers.

SMEs are considered an important and integral part of every country's economy, the fastest-growing sector of many economies, more flexible and adaptable in terms of structure and having a faster speed of response than larger organizations (Tagliavini, Ravarini, \& Antonelli, 2001). SMEs are often associated with nations' higher economic growth (Reynolds, 1997; Robson \& Bennett, 2000). According to Beck, Demirguc-Kunt, and Levine (2005), the share of SMEs employment of total manufacturing employment is associated with higher rates of gross domestic product (GDP) per capita growth. The existence of a large SMEs sector should be considered a characteristic of successful economies. However, in a relatively recent study, Ayyagari, Beck, and Demirguc-Kunt (2007) analyzed the relationship between the relative size of the SMEs sector to total employment in manufacturing and GDP across 76 countries. By presenting comprehensive statistics using a cut-off of 250 employees, Ayyagari et al. (2007) showed that on average in these countries, SMEs' contribution to the labor force constitutes $54 \%$ of the economy. The impact of SMEs on employment is significant. On the other hand, compared to large enterprises, SMEs typically have fewer financial resources, lower technical expertise, and more limited management skills (Blili \& Raymond, 1993). Therefore, it is increasingly important to study SMEs perspectives on the Chinese market. Growth (Muhos, Kess, Phusavat, \& Sanpanich, 2010) is a critical issue for SMEs' long-term survival and development toward large-scale companies, and sourcing from China may provide opportunities for speeding up this complicated process.

The aim of this study is to learn from the companies that have experience sourcing from China, and to provide practical guidelines for SMEs. This study may help SMEs function more effectively and efficiently in the Chinese market. More information is needed on how to source from China and what needs to be taken into account. Further, this study aims to clarify managing the sourcing process from the Finnish SMEs' perspective. There are still many complexities in international sourcing. For example, long lead times, environmental uncertainty, lower levels of quality, extension of supply lines, delivery risk, cultural differences, and sourcing professionals' lack of skills and capabilities are among the biggest impediments in global sourcing. Sourcing from China may be important to a firm's competitive position as a means to access raw materials, improve quality, lower cost, or access technology. The research questions of this study can be articulated as follows:

(1) What are the drivers for Finnish SMEs to start sourcing from China?

(2) What kind of challenges and advantages were faced in sourcing from China?

In this study, the case study was selected as a potential strategy to answer the main research questions. According to Yin (1989, p. 23), “a case study is an empirical inquiry that: investigates a contemporary phenomenon within its real-life context; when the boundaries between phenomenon and context are not clearly 
evident; and in which multiple sources of evidence are used”. Employees at eight case companies located in northern Finland were interviewed and analyzed.

This study consists of five parts. In the introduction, the background, motivation, research problem, and research questions are presented. In the second section, the theoretical part of this study, a short introduction to the Chinese market, the sourcing perspective, and the drivers with the most potential and challenges related to sourcing are presented. In the third section, the study method is described. In the fourth section, through describing and analyzing the eight case studies, the answers to the research questions are provided. Finally, in the discussion part, the main results, limitations, and further research topics are covered.

\section{Sourcing From China-Perspectives}

China is a world's fastest-growing economy (Kettunen et al., 2008). The economic growth started in the early 1980s when China opened its markets, and since then, many Western companies have been interested in Chinese markets. China is the second largest economy in the world after the United States and Japan, and accounts for $7.5 \%$ of the world's total economic activity. The Chinese market has grown very fast, and this quick growth has affected the country's economy in many ways. Personal income levels have increased in China, and competition has grown. China finds it challenging to train and develop its human resources. Consumers are more demanding, and they insist on high-quality products. Foreign investors have become more interested in Chinese market: usually expanding markets and low labor costs are the main factors why Western companies want to invest in China. In addition, Finnish companies have started to pay attention to Chinese markets, and in the 1990s, large companies moved to China, followed by SMEs in the 2000s. China has maintained its position as Finland's sixth largest trade partner, and China is also Finland's largest trade partner in Asia.

\section{Chinese Market}

China constitutes an important country for sourcing, and in today's global economy, China is increasingly seen as a key area for international sourcing (Salmi, 2006). Finnish companies started to do business in China in the 1950s. Large companies started to move to China gradually in the 1980s, but the big wave of investment happened in the 1990s, when subcontractors and contract manufacturers were forced to follow their customers. SMEs moved to China mainly in the 2000s.

As China has opened up its economy to foreign investors, transnational corporations have become interested in China's enormous market for goods and services (Roy, Walters, \& Luk, 2001). China and its reforming markets have increasingly attracted the attention of Western companies, because of its expanding markets and low labor costs. China constitutes an important country for sourcing, and in today's global economy, China is increasingly seen as a key area for international sourcing. According to Nassimbeni and Sartor (2006), China's success is driven not only by its low labor costs. The country's success is the result of strategic planning, the outcome of a logistic system that, if not perfect, is better by far than any other system in developing countries. China means strong internal competition, pride, and the ambition to become the strongest economy in the world (Salmi, 2006). However, unforeseen events, surprises, risks, and delays are possible. The lure of enormous markets and profits in China comes entangled with sources of risks and uncertainties.

To succeed in China, a Chinese partner plays a key role. Specifically, foreign firms making their initial entry into Chinese markets have found it almost impossible to succeed without a Chinese partner (Wong \& Maher, 1997). Guanxi is a key concept for understanding social behavior in China, especially the link between 
interpersonal relations and the attainment of desirable resources, and entails a strong social obligation to do favors for another person. The development of personal trust is highly important in China (Björkman \& Kock 1995). The Chinese business environment differs from the environment of Western firms and creates different challenges. One way to learn about Chinese markets is to be present in China and acquire knowledge of the Chinese market. There are two different ways to manage cultural distance; either the company uses a trustworthy partner familiar with Chinese business culture (intermediaries, an agent) or the company itself invests in building and nurturing long-term business relations. The way for Western companies to ensure and increase commitment from the Chinese side is to build up personal relations. Personal relations are also important for overcoming barriers in communication.

\section{Sourcing Perspectives}

Managing the sourcing task in the supply chain is a challenge for many corporations (Karpak, Kumcu, \& Kasuganti, 2001). In an increasingly competitive business world, global competition puts high demand on the flexibility of industrial companies. As a result of worldwide competition, firms are combining domestic and international sourcing as a means of achieving a sustainable competitive advantage. Organizations have realized that a world-class global supply base is required to meet world-class competition. The catalyst for global sourcing has been the worldwide competitive pressure forcing firms to reduce costs and to improve quality and responsiveness (Gelderman \& Semeijn, 2006). The need to gain a global competitive edge on the supply side has increased substantially. Particularly for companies that spend a high percentage of their sales revenue on parts and material supplies, and whose material costs represent a larger portion of total costs, savings from supplies are of particular importance. Moreover, the emphasis on quality and timely delivery in today's globally competitive marketplace adds a new level of complexity to outsourcing and supplier selection decisions. Many companies attempt to streamline the number of suppliers from which they source (Karpak et al., 2001). Purchasing is the key intermediary between members of the supply chain. Purchasing must serve an integral, if not a primary, role in managing the supply chain (Carr \& Smeltzer, 1999).

Quintens, Pauwels, and Matthyssens (2006), conceptualized the sourcing process, and defined four phases: (1) the investigation of purchase markets and the screening of potential suppliers; (2) the selection of supplies; (3) the negotiation and contraction; and (4) supplier evaluation and follow-up. Coordinating purchasing encompasses creating synergies from economies of scale, scope, process, and learning.

Companies have changed their focus from a short-term transactional sourcing concept to a supply chain management approach where they concentrate on developing long-term relations with suppliers, including forming partnerships that result in improved coordination of supplier networks (Karpak et al., 2001). Supplier relationships connect the company's internal configuration of supply with the external resources of its suppliers. Therefore, interaction in relationships and, for instance, the skills of the interacting personnel come to play a critical role in ensuring efficient supply. Indeed, attention on the supply side has shifted from product features to external issues: supply management increasingly stresses, for example, a process focus and a market focus (Salmi, 2006).

The drivers for international (or global) sourcing can be, for example, decreasing tariffs, improving transportation, communications and information technology, globalization of products, services and markets, global competition, and economic regionalism (Pennanen, Muhos, Wang, \& Kess, 2011). International competition has increased, and now services and products are available worldwide. Firms have to offer greater 
product and service quality at lower cost in order to remain competitive. Moreover, companies need to work more closely with their suppliers and customers.

In international sourcing, buyer-supplier relationships take time to establish. During this process, a key issue firms must address is effective management of the supplier network, including identification of supplier selection criteria, supplier selection decisions, and monitoring of supplier performance. Supplier selection decisions determine the number and identity of vendors that should be selected as supply sources and how order quantities should be allocated among the selected vendors. Vendor selection is inherently a complex decision. The decision process involves more than one criterion: Products have many attributes such as price, quality, service, and more, and members of sourcing committees bring diverse criteria to sourcing decisions driven by departmental interests such as cost, reliability, and delivery. These factors affect the selection complexity (Karpak et al., 2001).

Potential challenges in global sourcing have been mentioned by several authors (Mentzer, 2001; Fredriksson \& Jonsson, 2009; Salmi, 2006):

As presented in Table 1, there are many complexities in global sourcing. Long lead times, extension of the supply chain, environmental uncertainty, lower levels of quality, delivery risk, cultural differences, and sourcing professionals' lack of skills and capabilities required to manage globally are among the biggest impediments in global sourcing. Global sourcing may be important to a firm's competitive position as a means to access raw materials, improve quality, lower cost, or access technology. Pursuing a global procurement strategy successfully requires that a firm possess a supply chain orientation and the skills to deal with the complexities and uncertainties of the global environment.

Table 1

Potential Challenges in Sourcing From China

\begin{tabular}{|l|l|}
\hline Internal challenges & External challenges \\
\hline - Weak international sourcing skills and capability & - Extended supply chain and long lead times \\
- Lack of international sourcing management skills and & - Uncertainty of business environment and unpredictable inflation \\
capability & and exchange rates \\
- Lack of international sourcing strategy & - High levels of government intervention \\
- Lack of information technology fit for international & - Quality challenges and delivery challenges \\
sourcing & - Geographic distance and different time zone \\
- Language skills and capabilities & - High logistics and transaction costs \\
- Cultural skills and capabilities & - Cultural distance \\
\hline
\end{tabular}

\section{The Method}

This is a multiple case study with holistic strategy. The case study followed the process presented in Figure 1.

The unit of analysis in this study is SMEs with experience in sourcing from China. The definition of an SME is different in different contexts. The US context, for example, offers many definitions of SME depending on the industry. For example, in some industries, an SME is a company having fewer than 500 employees. In the European context, an SME is a company having fewer than 250 employees. This difference in definitions needs to be taken into account when studying the SME-related literature. The variations in defining an SME cause some confusion in the field of SME research. Ayyagari et al. (2007, p. 416) covered this topic in his globally focused, statistical study on SMEs: The term SME covers a wide range of definitions and measures, varying from country to country and varying between sources reporting SME statistics. Some of the commonly 
used criteria are the number of employees, total net assets, sales, and investment level. However, the most common basis for definition is employment, and here again, there is variation in defining the upper and lower size limit of an SME. Despite this variance a large number of sources define an SME to have a cut-off of 250 employees (Ayyagari et al., 2007). Because of the case context, the European definition is used. Within the SME category, the European Union defines medium-sized firms as having 50-249 employees, small firms as having 10-49 employees, and micro-firms as having 0-9 employees (Storey, 2003).

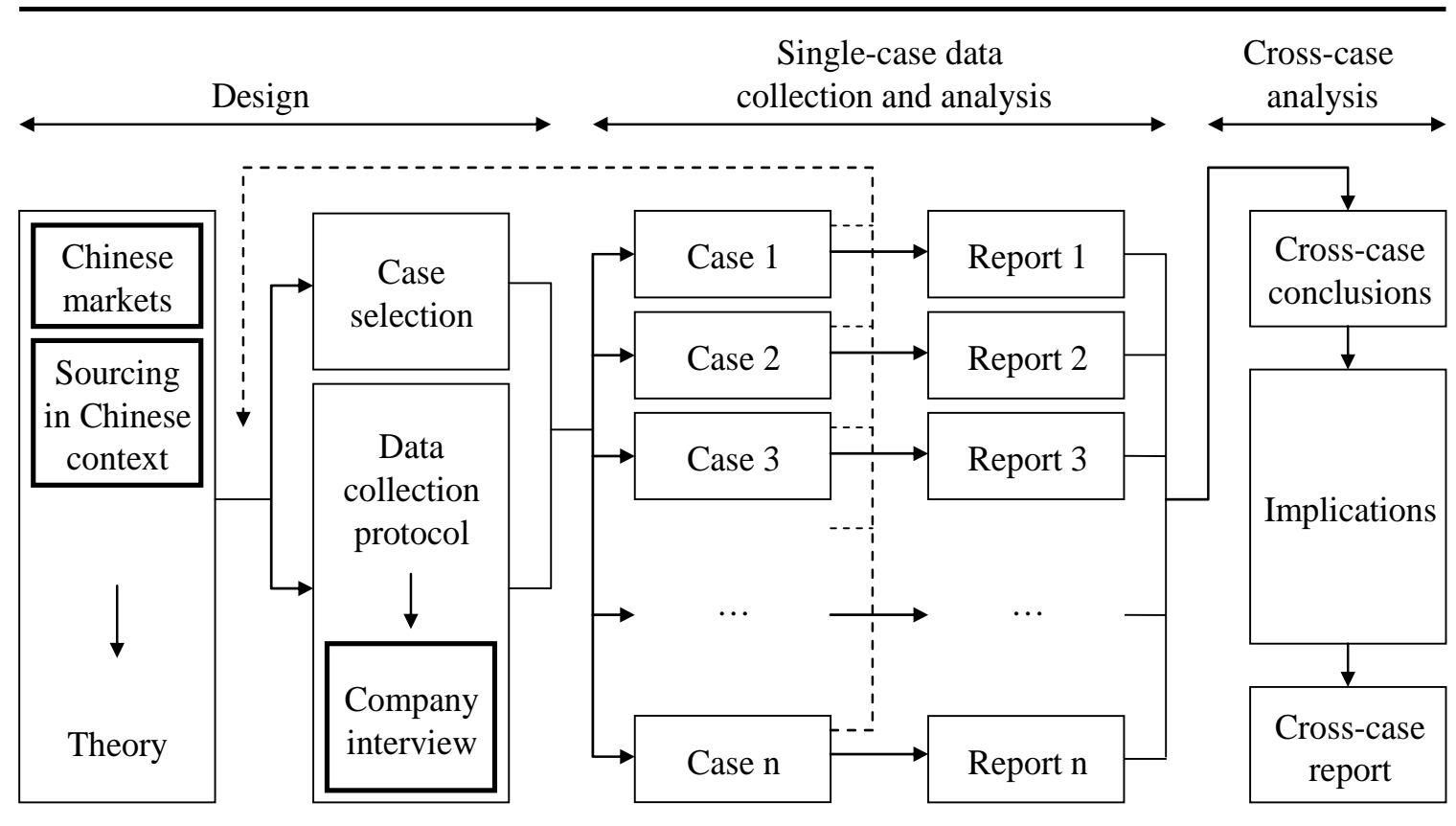

Figure 1. The research process (modified from Yin, 1989).

The case study evidence was collected by two separate studies (Karjalainen et al., 2010; Pennanen et al., 2010) in the first and the second quarters of 2010. The studies were conducted using similar research process and questionnaires. The case study evidence is further analyzed and synthesized through this analysis.

\section{The Case Studies-Perspectives From Finnish SMEs}

The case study was carried out in eight SMEs located in northern Finland. The basic information on the case companies is presented in Table 2.

Table 2

The Case Companies-Basic Information

\begin{tabular}{|l|l|l|l|}
\hline Case & SME category & Industry & Sales (year 2009) \\
\hline A & Small company & Business-to-business wholesale trade & 10 million $€$ \\
B & Medium-sized company & Mechanical industry -steel and aluminium products & 35 million $€$ \\
C & Medium-sized company & Wholesale trade and import of non-eatable products & 50 million $€$ \\
D & Small company & Manufacturing of metal products & 2 million $€$ \\
E & Small company & Custom made training and racing clothes & 3 million $€$ \\
F & Medium-sized company & Injection moulding and mould manufacturing & 15 million $€$ \\
G & Micro company & Contract manufacturing and design for high-end technology leaders & 30 thousand $€$ \\
H & Medium-sized company & Manufacturing of safety cabins & 55 million $€$ \\
\hline
\end{tabular}

Case A started sourcing from China in the early 1990s. The main focus is sourcing bearings, the 
company's main product. In the beginning, the drivers for starting sourcing from China were pressure for lower prices, lowered product origin sensitivity among customers, willingness to respond to customer needs, and the company's open-mindedness. The advantages of the Chinese market have been low costs of products, low labor cost, fast response, fast delivery, sufficient quality, customer service attitude, resources available for product development, and location near customers that have also moved functions to China. Based on company A's experiences, some challenges were faced. Among these challenges were some quality problems, long physical distance, and different time zone.

Case B started sourcing from China in 2007. The focus is sourcing steel products, components, and plastic products. The main drivers for starting sourcing from China were low costs of products, tools, labor, and raw material, domestic suppliers' high prices, typically fast response to orders, and managers' positive earlier China experiences. Based on company B's experiences, there were a couple of challenges related to sourcing. Among the challenges were quality challenges, long delivery times, problems in delivery management, extra inventories, and constricted communication interface. Chinese suppliers' unwillingness to shorten delivery times has been a significant challenge.

Case C started sourcing from China in the 1960s. The company's first experiences were related to Hong Kong, and then the sourcing was extended to mainland China. The focus has been sourcing of wholesale products. The main drivers for starting sourcing from China were low cost of the product, sufficient quality, competitive price-quality ratio, and sufficient logistics (compared with other countries). Based on company C's experiences, there were a couple of challenges related to sourcing. Among these challenges were unexpected government intervention (tax refund restriction), bureaucracy in Finland and the EU (i.e., protectionist taxes), sudden closure of the supplier, intellectual property problems, agreement problems, and a language barrier.

Case D started sourcing from China in 2001. The focus is sourcing specific hard metal products. The main drivers for starting sourcing from China were managers' strong experience on international sourcing, managers' strong experience selecting the source, favorable exchange rates, low cost of raw material, low cost of product, low cost of tools, availability of raw material, sufficient quality of product, fast delivery, improved reliability of delivery, flexibility in tailored products, and good motivation for collaboration. Based on company C's experiences, there were a couple of challenges related to sourcing. Among these challenges were risk of becoming short-changed, risk of being bypassed in the supply chain, extra resources tied to quality control, and complicated payment methods.

Case E started sourcing from China in 2004. The focus is sourcing customized training and racing clothes. The main drivers for starting sourcing from China were rising costs of earlier suppliers, the owner's good connections to Chinese suppliers, low labor cost, low material cost, availability of material, and the Chinese supplier's good industry-specific knowledge. Based on company E's experiences, there were a couple of challenges related to sourcing. Among these challenges were problems in keeping promises, extra resources tied to quality control, quality problems, poor delivery reliability, and long delivery time.

Case F started sourcing from China mainly in the 1990s. The focus is outsourcing molds. However, other types of sourcing, such as sourcing of raw materials, are also needed. The main drivers for starting sourcing from China were the need to respond to increasing price competition, competitors sourcing from China, need to increase volumes, lack of suppliers in other countries, delivery reliability, precise culture, Chinese high morale in working, and high-level technology knowledge and potential resources for product development. Based on 
company F's experiences, there were a couple of challenges related to sourcing. Among these challenges were long physical distance, variable costs of logistics, and constricted communication interface.

Case G started sourcing from China soon after being founded (2004). The focus is sourcing electrical semi-products, cables, parts, and connectors. The main drivers for starting sourcing from China were a manager's earlier experience in business with Chinese companies, sufficient quality, and low price of the product, the Chinese work ethic, and very rapid response in communication. Based on company G's experiences, there were some challenges related to sourcing. Among these challenges were poor English language skills in China and culture-related communication challenges especially situations where advice is needed.

Case H started sourcing from China in 2004. The focus is sourcing metals, glasses, tire products, coupling gears, steering wheels, lights, etc.. The main drivers for starting sourcing from China were low price of the product, quality of operations, the high Chinese work ethic, high commitment, excellent level technical expertise, respect for customers, and accuracy. Based on company G's experiences, there were some challenges related to sourcing. Among these challenges were time-consuming trust and relationship building, sudden closure of the supplier (and loss of moulds), long physical distance, and costs of extra inventories.

On the one hand, the case companies had many drivers for starting sourcing from China and maintaining that option in the long run. The main drivers toward sourcing from China are presented in Table 3.

Table 3

Drivers for Sourcing From China

\begin{tabular}{|l|l|}
\hline Internal drivers (cases) & External drivers (cases) \\
\hline - Willingness to respond to customer needs (A) & - Low costs of product (A, B, C, G, H) \\
- Open-mindedness of the company (A) & - Low labor costs (A, B) \\
- Lowered sensitivity to product origin (A) & - Production near customers (A) \\
- Managers' positive China experiences (B, G) & - Fast delivery (A, D) \\
- Managers' strong experience in international sourcing (D) & - Fast response in communication (A, B, G) \\
- Manager's strong experience in selecting product sourced (D) & - Sufficient quality (A, C, D, G) \\
- Need to increase volumes (F) & - Customer service attitude/motivation (A, D, G, H) \\
& - Resources for product development (A, F) \\
& - Low cost of tools (B, D) \\
& - Low raw material cost (B, D) \\
& - High-cost domestic suppliers (B) \\
& - Price-quality ratio (C) \\
& - Sufficient logistics (C) \\
& - Favorable exchange rates (D) \\
& - - Availability of raw material (D) \\
& - Improved reliability of delivery (D) \\
& - Flexibility in tailored products (D) \\
& - Increasing price competition (F) \\
& - Competitors sourcing from China (F) \\
& - Lack of suppliers in other countries (F) \\
& - Delivery reliability (F) \\
& - Precise culture (F, H) \\
& - Chinese high work ethic (F, G, H) \\
& - High-level technology knowledge (F, H) \\
& - Quality of operations (H) \\
& - High commitment of Chinese suppliers (H) \\
&
\end{tabular}

On the other hand, the case companies faced many challenges and complexities. The challenges faced in sourcing from China are presented in Table 4.

As a conclusion of the empirical part, Finnish SMEs faced strong drivers for sourcing from China as well 
as many challenges on the way to building a successful supply chain from the Chinese market to Finland.

Table 4

Challenges Faced When Sourcing From China

\begin{tabular}{|l|l|}
\hline Internal challenges (Cases) & External challenges (Cases) \\
\hline - Problems in delivery management (B) & - Quality problems (A, B, E) \\
- Extra inventories (B, H) & - Long physical distance (A, F, H) \\
- Extra resources tied to quality control (D) & - Different time zone (A) \\
& - Long delivery time (B, E) \\
& - Constricted communication interface (B, F) \\
& - Unexpected government intervention (C) \\
& - Bureaucracy in Finland and the EU (C) \\
& - Unexpected closure of the supplier (C, H) \\
& - IPR -problems (C) \\
& - Agreement problems (C) \\
& - Language barrier (C) \\
& - Risk of becoming short-changed (D) \\
& - Risk of being bypassed in the supply chain (D) \\
& - Complicated methods of payment (D) \\
& - Problems in keeping promises (E) \\
& - Extra resources tied to quality control (E) \\
& - Poor delivery reliability (E) \\
& - Changing costs of logistics (F) \\
& - Cultural distance (G) \\
& - Communication problems (G) \\
& - Time-consuming trust and relationship building (H) \\
\hline
\end{tabular}

\section{Discussion}

The aim of this study was to describe the experiences of Finnish SMEs sourcing from China. Eight cases located in northern Finland were studied to point out the common drivers for sourcing as well as the common headaches. As a result of this study, the main drivers and challenges related to the process were analyzed and evaluated. The answers to research questions 1 and 2 can be condensed into a table of common drivers and challenges:

\section{Table 5}

The Drivers and Challenges in Finnish SMEs Sourcing From China

\begin{tabular}{|l|l|l|l|}
\hline The main drivers & Cases & The main challenges & Cases \\
\hline Low costs of product & 5 & Quality problems & 3 \\
Sufficient quality & 4 & Long physical distance & 3 \\
Respect of customers & 4 & Long delivery time & 2 \\
High work morale & 3 & Poor communication interface & 2 \\
Fast response in communication & 3 & Unexpected closure of supplier & 2 \\
Fast delivery & 2 & Grown inventories & 2 \\
Precise culture & 2 & & \\
Low cost of tools & 2 & & \\
Low labour costs & 2 & & \\
Low raw material cost & 2 & & \\
Positive experience of managers & 2 & & \\
Product development resource & 2 & & \\
High technology knowledge & 2 & & \\
\hline
\end{tabular}

The managers of the Finnish SMEs recognized more drivers than challenges as they described their approach to establishing a sourcing channel between China and Finland.

The most common group of drivers was related to low costs: not only the low costs of the product sourced 
but also the labor, tool, and raw material costs. Sufficient quality played an important role as well; without sufficient product quality, the investment would not have paid for itself. Although sufficient quality meant different things for different cases, not one company seemed to be willing to pay for "over-quality". Respect for customers and good work ethic were important drivers as well and were backed up by the earlier positive experiences of managers in some cases. Fast response and fast delivery times were pointed out by some of the managers; these drivers seemed to fit with the precise culture mentioned in two cases. Finally, the high technological expertise of Chinese suppliers was found a positive driver; this notion was supported by the notion that two managers saw a Chinese supplier as an important resource for product development collaboration.

A couple of challenges were noted in more than one of the cases. Quality problems were noted as an important challenge; this notion was supported with the notion of extra resources tied to quality control. This seems to conflict with the "sufficient quality" driver. Long physical distance was seen as an important challenge as well: partly because of the fact that some cases suffered long-than-expected delivery times. In some companies, this led to extra inventory and extra costs. Two companies faced the unexpected closure of a supplier, which practically meant the loss of resources invested in these suppliers. Finally, the communication interface between partners was seen as poor and constricted by technological or human barriers.

This analysis may support managers of Finnish SMEs considering sourcing from China in their critical decision. The viewpoints pointed out by managers with experience in sourcing may shed light on the factors that need to be taken into account before making a decision and while developing a sourcing process between China and Finland. The results of this analysis represent the viewpoint of SMEs functioning with fewer financial resources, lower technical expertise, and more limited management skills: this viewpoint is often different from the viewpoint of large enterprises.

This analysis is based on a limited number of cases. A construct validity of the study is based on a research plan that has worked as a road map throughout the study. The case study used multiple sources of evidence. The synergy between quantitative and qualitative data was used. The chain of evidence was preliminarily defined in a research plan to strengthen construct validity. The internal validity of the study relies on the research design. In the theoretical part, the theoretical background was presented, and in the empirical part, the data was shown to enable analysis. The test of external validity shows that the study findings cannot be widely generalized because of the uniqueness of the cases. The research findings depend on the point in time when data is collected. Evaluation of the reliability highlights the following points. Reproducing the same case study in the same environment later would change some of the findings. A case itself has a significant role when the case study research method is used. In addition, the researchers' own paradigm or point of view inevitably affects the findings.

In future studies, it would be interesting to open more cases with more similar industrial backgrounds. The SMEs analyzed differed from each other in many ways, which weakens the applicability of the results. It would be interesting to compare the results of similar analysis conducted of SMEs located in other European countries or in the US. The role of intermediaries in supporting SMEs in this challenging area requires a closer look.

\section{References}

Ayyagari, M., Beck, T., \& Demirguc-Kunt, A. (2007). Small and medium enterprises across the globe. Small Business Economics, 29(4), 415-434. 
Beck, T., Demirguc-Kunt, A., \& Levine, R. (2005). SMEs, growth, and poverty: Cross-country evidence. Journal of Economic Growth, 10(3), 199-229.

Björkman, I., \& Kock, S. (1995). Social Relationships and business networks: The case of western companies in China. International Business Review, 4(4), 519-535.

Blili, S., \& Raymond, L. (1993). Information technology: Threats and opportunities for small and medium-sized enterprises. International Journal of Information Management, 13(6), 439-448.

Carlsson, J., Nordegren, A., \& Sjöholm, F. (2005). International experience and the performance of Scandinavian firms in China. International Business Review, 14, 21-40.

Carr, A., \& Smeltzer, L. (1999). The relationship of strategic purchasing to supply chain management. European Journal of Purchasing and Supply Management, 5, 43-51.

Fredriksson, A., \& Jonsson, P. (2009). Assessing consequences of low-cost sourcing in China. International Journal of Physical Distribution and Logistics Management, 39(3), 227-249.

Gelderman, C., \& Semeijn, J. (2006). Managing the global supply base through purchasing portfolio management. Journal of Purchasing and Supply Management, 12, 209-217.

Karjalainen, T., Muhos, M., Wang, L., \& Kess, P. (2011). Kiinalaisten ja suomalaisten yritysten välinen tilaus-toimitusketju. Working Papers in Department of Industrial Engineering and Management 3/2011, University of Oulu, Department of Industrial Engineering and Management (in Finnish).

Karpak, B., Kumcu, E., \& Kasuganti, R. (2001). Purchasing materials in the supply chain: Managing a multi-objective task. European Journal of Purchasing \& Supply Management, 7, 209-216.

Kettunen, E., Lintunen, J., Lu, W., \& Kosonen, R. (2008). Suomalaisyritysten strategiat Kiinan muuttuvassa toimintaympäristössä. Helsingin kauppakorkeakoulun julkaisuja-HSE Print, B-98. Helsinki School of Economics: Helsinki (in Finnish).

Mentzer, J. T. (2001). Supply chain management. Sage Publications: Thousand Oaks: California.

Muhos, M., Kess, P., Phusavat, K., \& Sanpanich, S. (2010). Business growth models: Review of past 60 years. International Journal of Management and Enterprise Development, 8(3), 296-315.

Nassimbeni, G., \& Sartor, M. (2006). Sourcing in China. Houndmills: Palgrave Macmillan.

Pennanen, M., Muhos, M., Wang, L., \& Kess, P. (2011). Supply chain management between Finland and China: Empirical evidence from Vaasa region. Working Papers in Department of Industrial Engineering and Management 2/2011, University of Oulu, Department of Industrial Engineering and Management: Oulu.

Quintens, L., Pauwels, P., \& Matthyssens, P. (2006). Global purchasing strategy: Conceptualization and measurement. Industrial Marketing Management, 35, 881-891.

Reynolds, P. (1997). New and small firms in expanding markets. Small Business Economics, 9(1), 79-84.

Robson, P., \& Bennett, R. (2000). SME growth: The relationship with business advice and external collaboration. Small Business Economics, 15(3), 193-208.

Roy, A., Walters, P., \& Luk, S. (2001) Introduction to the Special Issue on "Doing business in China”. Journal of Business Research, 52, 93-94.

Salmi, A. (2006). Organising international supplier relations: An exploratory study of western purchasing in China. Journal of Purchasing and Supply Management, 12, 197-208.

Storey, D. J. (2003). Entrepreneurship, small and medium sized enterprises and public policy. In Z. J., Acs, \& D. B. Audretsch (Eds.). International Handbook of Entrepreneurship Research. Dordrecht, 473-511.

Tagliavini, M., Ravarini, A., \& Antonelli, A. (2001). An evaluation model for electronic commerce activities within SMEs. Information Technology and Management, 2(2), 211-230.

Wong, Y., \& Maher, T. (1997) New key success factors for China’s growing market. Business Horizons, May-June.

Yin, R. (1989) Case study research: Design and methods. Beverly Hills: Sage Publications. 